\title{
Reliability of fibre Bragg gratings in polymer optical fibre
}

H. Dobb, K. Carroll, D. J. Webb, K. Kalli, M. Komodromos, et al.

H. Dobb, K. Carroll, D. J. Webb, K. Kalli, M. Komodromos, C. Themistos, G. D. Peng, A. Argyros, M. C. J. Large, M. A. van Eijkelenborg, M. Arresy, S. Kukureka, "Reliability of fibre Bragg gratings in polymer optical fibre," Proc. SPIE 6193, Reliability of Optical Fiber Components, Devices, Systems, and Networks III, 61930Q (23 May 2006); doi: 10.1117/12.662313 


\title{
Reliability of fibre Bragg gratings in polymer optical fibre
}

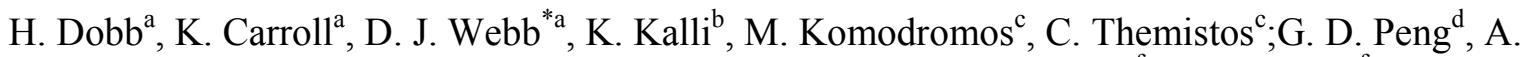 \\ $\operatorname{Argyros}^{\mathrm{e}}$, M. C. J. Large ${ }^{\mathrm{e}}$, M. A. van Eijkelenborg ${ }^{\mathrm{e}}$, M. Arresy ${ }^{\mathrm{f}}$, S. Kukureka ${ }^{\mathrm{f}}$. \\ aphotonics ResearchGroup, Aston University, Birmingham, UK \\ ${ }^{\mathrm{b}}$ Higher Technical Institute, Cyprus \\ Frederick Research Centre, Cyprus \\ ${ }^{\mathrm{d}}$ University of New South Wales, Australia \\ ${ }^{\mathrm{e}}$ University of Sydney, Australia \\ ${ }^{\mathrm{f}}$ University of Birmingham, UK
}

\begin{abstract}
In this paper we report on investigations of some of the factors that have a bearing on the reliability and repeatability of polymer fibre Bragg gratings. The main issues discussed are the fibre preform composition, the fibre drawing conditions and the thermal history of the fibre grating.
\end{abstract}

Keywords: Polymer optical fibre, PMMA, fibre Bragg grating, sensors, reliability.

\section{INTRODUCTION}

There is growing interest in the potential applications of fibre Bragg gratings recorded in polymer optical fibre (POF). Whilst there is scope in POF based communication systems for fibre Bragg grating (FBG) based filters, we feel that some of the most significant applications may be in the area of optical fibre sensing due to some unique features of plastic fibre:

- Physical properties. POF is capable of surviving much higher strains than silica fibre, suggesting its use in situations where this is an issue. Equally, POF based Bragg grating sensors are an order of magnitude more sensitive to temperature than silica fibre ${ }^{1}$.

- Chemical properties. POF lends itself potentially to modification by a wide spectrum of organic chemical techniques that cannot be used with silica fibre.

- Biocompatibility. Polymer fibres are far more attractive than silica fibre for in-vivo applications; clinicians are already used to the idea of inserting polymer catheters into the body, where a silica fibre breakage could be serious.

Whilst the first POF Bragg grating (POFBG) was reported a few years ago ${ }^{2}$, the field is still very much in its infancy in comparison to the silica technology. In terms of the reliability and repeatability of POF based devices there is a considerable amount of fundamental research that needs to be done. In this paper we will discuss some of the factors affecting the reliability of POFBGs and report on our current research in this area. In addition to looking at aspects of the fibre production process, we have been focussing on the effects of temperature cycling on the grating properties in a study which, in order to provide some generality, involves both step-index POF manufactured at the University of New South Wales, Australia and microstructured POF produced at the University of Sydney, also in Australia. For FBGs recorded in both types of fibre, we have observed hysteresis in the temperature dependence of the Bragg wavelength shift, which seems to be symptomatic of a thermal annealing process.

\section{FIBRE PRODUCTION}

In order to produce POFBG based devices with reproducible behaviour, it is essential to ensure that the properties of the fibre itself are well characterised. With silica fibre this issue was resolved long ago. The cladding material is of very

*d.j.webb@aston.ac.uk; phone: +44 (0)121 204 3541; http://www.ee.aston.ac.uk/research/prg/index.html 
high purity and uniformity, and the quantities of dopants added to the core are controlled to high precision. The situation is much less simple in the case of polymeric materials. We shall restrict discussion to the commonly used polymethylmethacrylate (PMMA), but the issues to be discussed here apply to any polymers. The polymerisation process used can ultimately affect two different parameters of the polymer produced: the molecular weight and the degree of cross linkage between the polymer chains.

Amongst other things, the average molecular weight has a considerable influence on the ease of drawing the fibre, with it being suggested that a mean molecular weight in the range of 60,000-100,000 is most suitable ${ }^{3}$. The mean molecular weight is not usually well specified - or indeed well controlled - for commercial PMMA, so this is an important issue. As an example, at Aston University we have been studying the effects of the drawing process on the physical properties of the resulting fibre in an attempt to optimise those properties for POFBG based sensing. Several series of experiments have been carried out on homogeneous extruded PMMA rods obtained from Amari plastics ${ }^{4}$; at one stage a second order for nominally identical rods was placed, but on receipt it was noted that the second batch seemed to be easier to work with, in the sense that there was less of a tendency for bubbles to form in the rod while it was in the oven. Samples of the two batches were submitted to Rapra technology ${ }^{5}$ for characterisiation using gel permeation chromatography, and the results provided by them are shown in figure 1 .

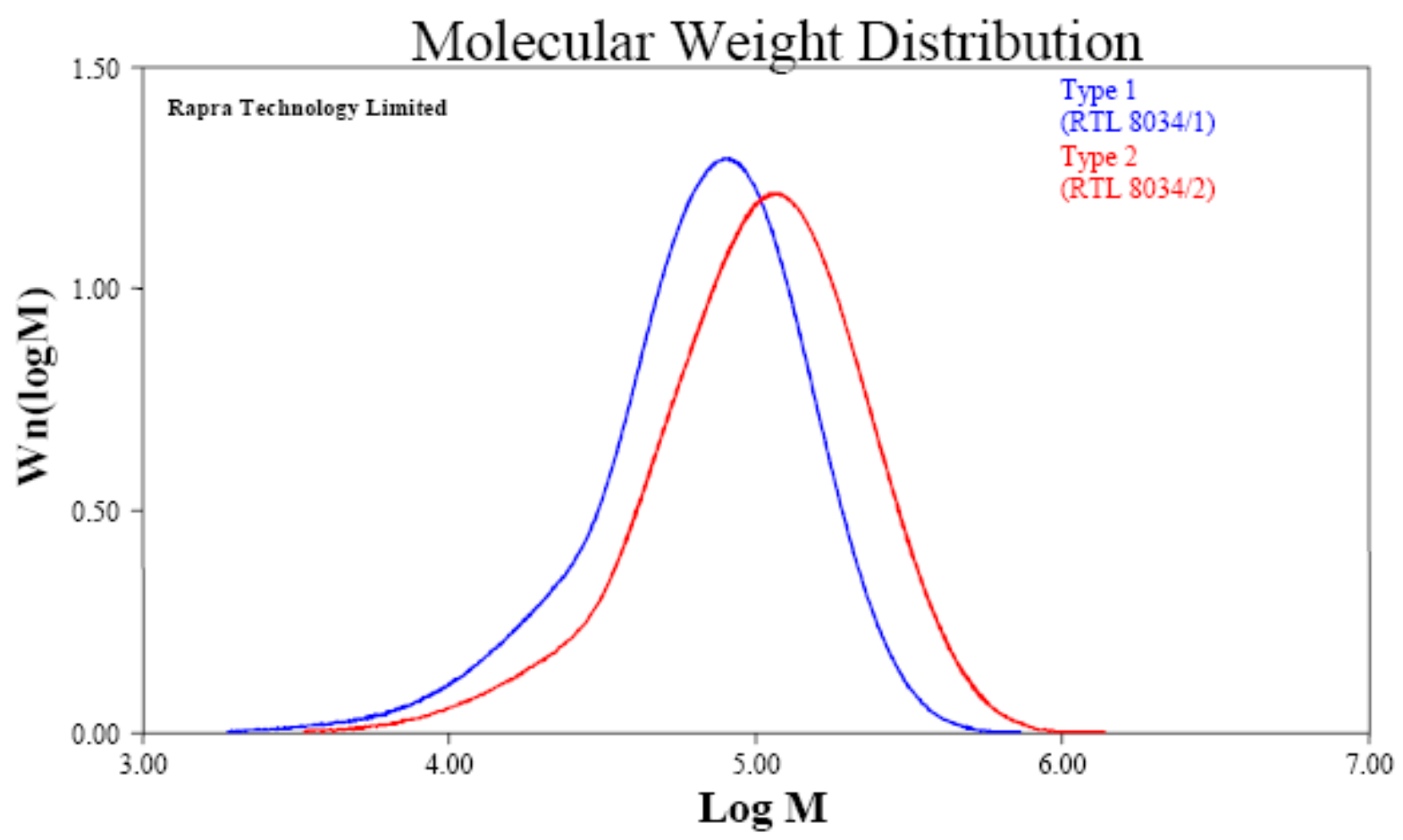

Figure 1: Molecular weight distributions of two batches of nominally identical PMMA rods.

The average molecular weights of the two samples were 87,000 and 133,000 . This experience clearly indicates a need to have close control over the preform production process.

It is known that the fibre drawing conditions can considerably influence the physical properties of the fibre ${ }^{6}$. Our interest in this aspect stems from our desire to use POFBGs for sensing high levels of strain. Pristine silica optical fibre can survive strains of up to around $6 \%$, however, the stripping of the fibre coating associated with the inscription of fibre Bragg grating strain sensors tends to reduce the yield stress and it is common to expect a working maximum strain of around $1 \%$. There are a number of applications where the strains encountered can easily exceed this value; for 
example, many modern composite materials can survive much higher strains. Consequently, we have been investigating how the yield strain of POF is influenced by the drawing conditions.

Experiments were carried out using 15 and $25 \mathrm{~mm}$ diameter rods of PMMA obtained form Amari Plastics ${ }^{4}$. The rods were fed at $5 \mu \mathrm{m} / \mathrm{s}$ into a cylindrical oven, $10 \mathrm{~cm}$ in diameter and $25 \mathrm{~cm}$ in length, with a metal iris at the top and a $5 \mathrm{~mm}$ width slot at the bottom where the fibre emerged. Heating was obtained using an $8 \mathrm{~cm}$ wide ohmic band heater centered approximately $8 \mathrm{~cm}$ from the top of the oven. A thermocouple was used to monitor air temperature adjacent to the band heater. Fibre was pulled to a diameter of $150-250 \mu \mathrm{m}$ at a range of oven temperatures and then its tensile properties were characterised at the University of Birmingham in the UK. The results are shown in figure 2.

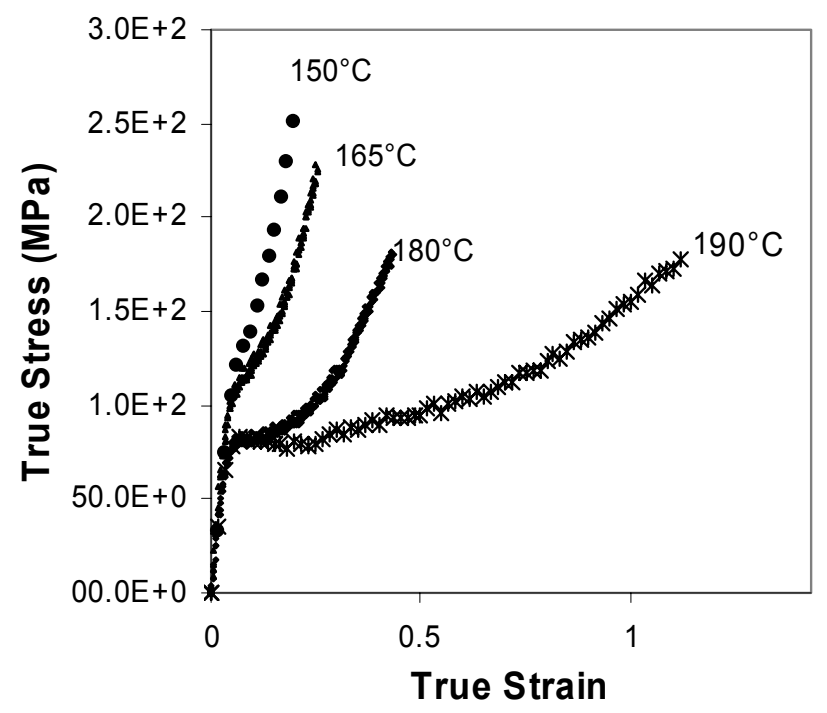

Figure 2: True stress as a function of true strain for fibre drawn at different temperatures.

Several conclusions may be drawn from these data. Firstly, although this is a little difficult to see from the figure, closer inspection shows that the oven temperature has very little effect on the elastic behaviour of the fibre, the elastic limit occurring at a strain of about $6 \%$ in all cases. Secondly, it may be seen that at higher drawing temperatures, the yield stress reduces. Finally, it is clear that the yield strain increases markedly with oven temperature (note that the true strain at which the $190^{\circ} \mathrm{C}$ fibre breaks is equivalent to an extension of around three times the original length).

The considerable change in the fibre properties at different drawing temperatures is associated with an alignment of the long polymer chains during the drawing process. At high temperatures, the viscosity in the melt region and consequently the fibre tension are low and the molecular orientation remains essentially random. Lower temperatures and a much higher viscosity result in a correspondingly higher fibre drawing tension and this is associated with a partial alignment of the molecular chains along the fibre axis. The much greater breaking strain of the high temperature fibre may then be understood by noting that once the fibre under tension enters the inelastic region, a considerable amount of strain is required before the molecules of this fibre become aligned to the same degree that they are in the low temperature fibre during the drawing process.

The extent of alignment in the drawn fibre may be observed by annealing the fibre at an elevated temperature when the fibre may shrink by a considerable amount. This effect is brought out in figure 3 where the dependence of both the yield strain and the degree of shrinkage post-annealing are shown as a function of drawing tension. To obtain these data, the fibre was annealed at a temperature of $120^{\circ} \mathrm{C}$ (above the glass transition temperature) for 2 hours. 


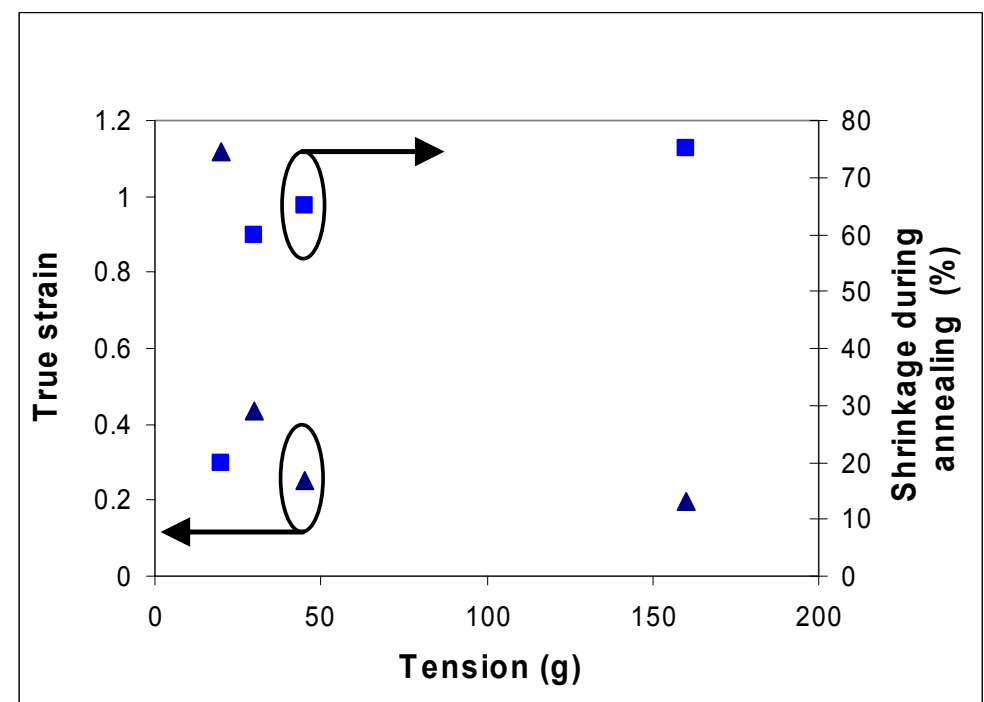

Figure 3: Dependence on the drawing tension of true strain (triangles) at yield point and shrinkage (squares) during annealing.

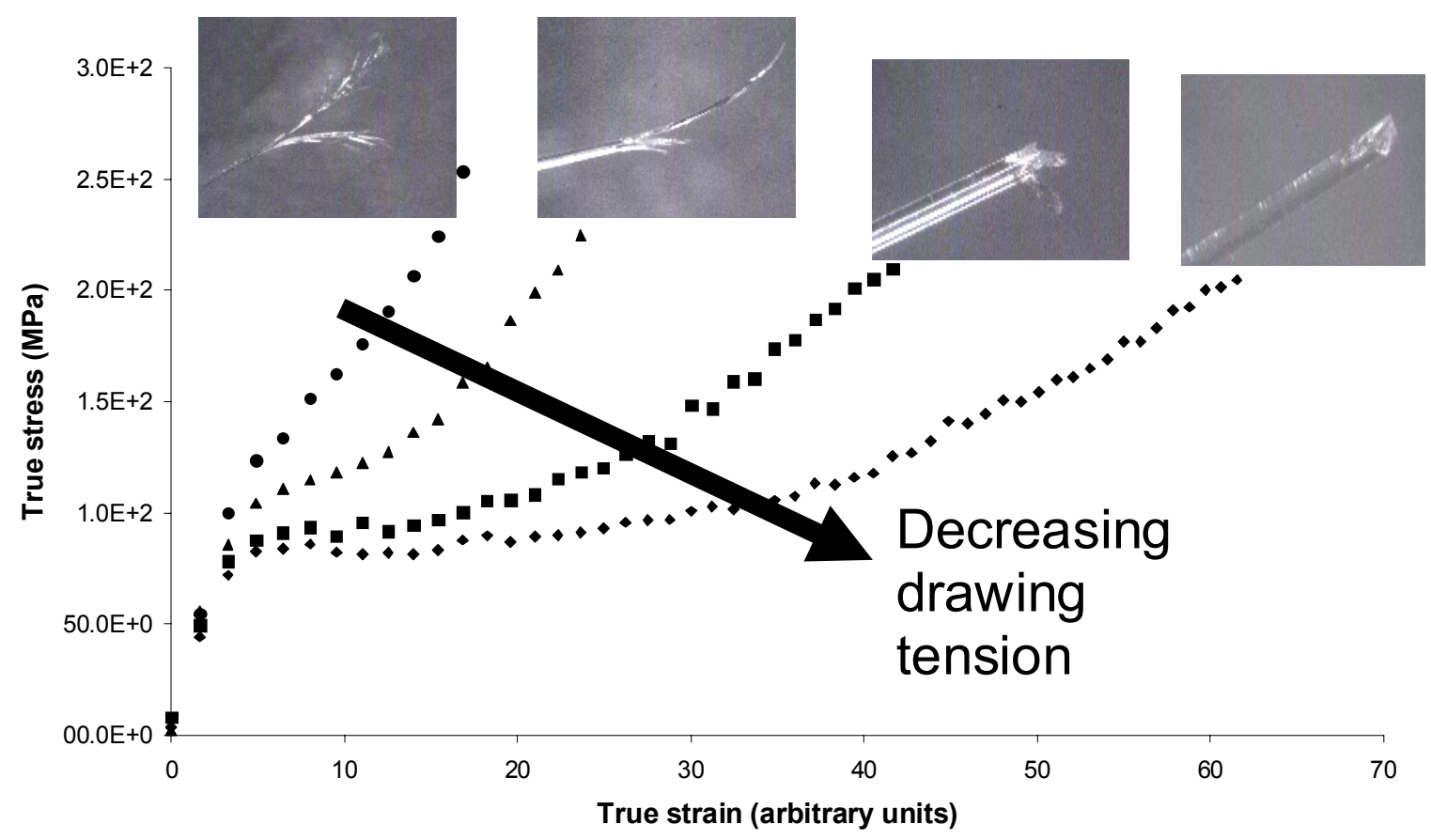

Figure 4: Influence of drawing tension on stress-strain curve (plots) and fibre ends (photographs).

Of prime importance to the molecular alignment process is the drawing tension. This is brought out in figure 4, where the oven temperature was held constant at $195^{\circ} \mathrm{C}$, but the fibre tension altered by adjusting the feed rates. The link 
between tension and yield strain is clear. Also shown in figure 4 are the fibre ends following breakage. It may be seen that the fibre drawn under high tension with a consequently high degree of molecular alignment suffers considerable fraying; an effect not seen in the fibre drawn under lower tension. This phenomenon is reproduced during cleaving of the fibre, where it is observed that fibre produced under high tension frays either immediately on cleaving or over a matter of hours or days. Such fibre is difficult to work with and for long term use it has been found necessary to glue such fibre into a capillary and then polish down the end.

The implication of the results presented above is clear: there is considerable benefit in ensuring that the fibre is produced with low tension. This both improves the yield strain of the fibre and at the same time minimises changes to the fibre geometry caused by any post-draw annealing.

\section{FBG FABRICATION}

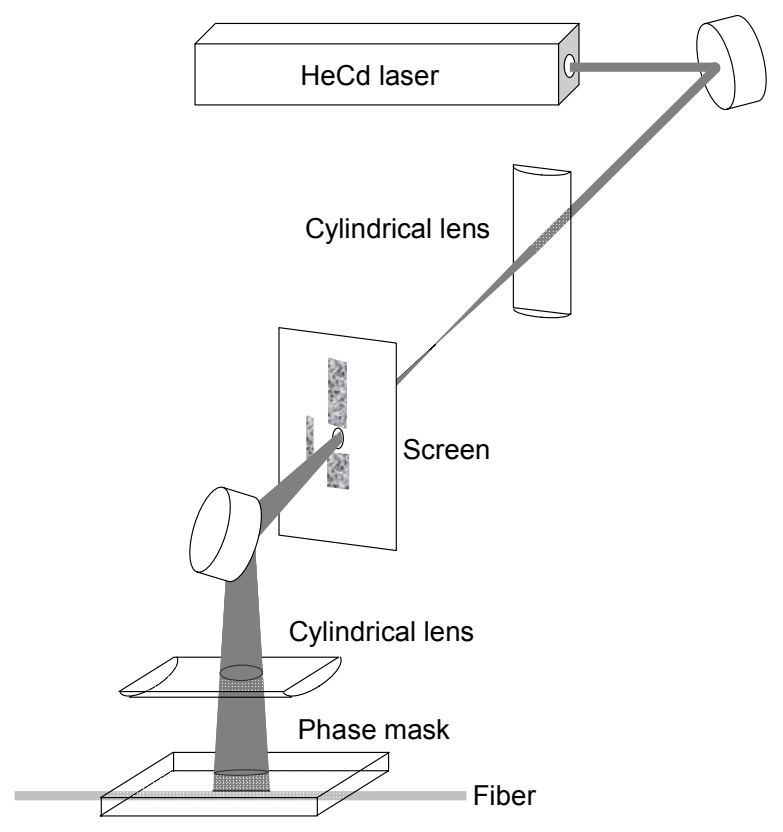

Figure 5: Schematic arrangement of FBG fabrication equipment.

A schematic of the inscription arrangement can be seen in figure 5. FBG inscription was undertaken with a $30 \mathrm{~mW}$ Kimmon IK series HeCd laser emitting at $325 \mathrm{~nm}$ by means of the standard phase mask technique, utilising a mask with a pitch of $1060.85 \mathrm{~nm}$ designed to produce a FBG in silica at around $1536 \mathrm{~nm}$. For successful fibre Bragg grating fabrication in polymer optical fibre, the fibre needs to be supported along its entire length in order to minimise the effects of air currents on the position of the fibre. Consequently, the fibre was rested on three v-grooves which were fixed on to two L-brackets; these in turn were attached to three axis translation stages. Two plano-convex cylindrical lenses with $10 \mathrm{~cm}$ focal lengths were incorporated in the system, one in the usual position before the phase mask, which served to focus the light down towards the core, and the other at a distance of $56.5 \mathrm{~cm}$ from the POF. The second lens was used to expand the approximately $1 \mathrm{~mm}$ diameter laser beam to cover approximately $1 \mathrm{~cm}$ of the POF. Without the second lens incorporated in the arrangement, FBGs of approximately $1 \mathrm{~mm}$ in length, the size of the laser beam, could be fabricated. Thus, the second lens provided some flexibly over the grating design.

Two different types of POF were investigated: a single mode step index POF and a single mode microstructrured POF. In order to monitor the fabricated gratings in reflection, a silica SMF $2 \times 2$ 50:50 coupler designed to operate in the telecommunications C-band was used. One arm of the coupler had an AFC/PC pigtail spliced on to it which was then 
aligned to couple light into the POF (small amounts of index matching gel minimised any Fresnel reflections and improved coupling to the POF). The grating growth during fabrication was monitored on an OSA by coupling an ASE light source (Thorlabs ASE-FL7002-C4, $5 \mathrm{~mW}$ output power, operating wavelength range of 1530-1610 nm) into the POF.

\subsection{Step index POF}

The single mode step index POF had core/cladding sizes of $12 / 240 \mu \mathrm{m}$, the core being constructed of methyl-ethylbenzyl methacrylate (MMA-EMA-BzMA) with the cladding made from polymethylmethacrylate (PMMA). In order to couple sufficient light into the fibre, the ends were embedded into stainless steel capillaries with a length of $1 \mathrm{~cm}$, inner diameter of $254 \mu \mathrm{m}$ and outer diameter of $1590 \mu \mathrm{m}$, using Norland Optical Adhesive No. 81. The fibre ends were then polished using aluminium oxide lapping film of diminishing abrasive sizes: $5 \mu \mathrm{m}, 1 \mu \mathrm{m}, 0.1 \mu \mathrm{m}$ and $0.05 \mu \mathrm{m}$.

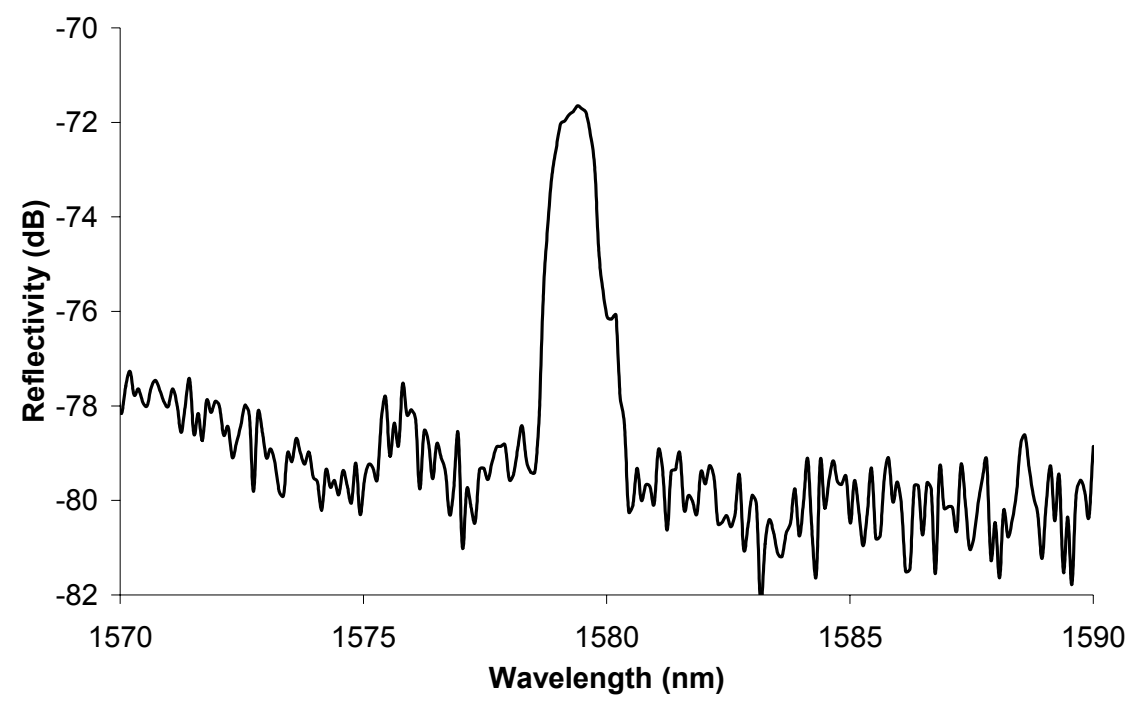

Figure 6: Spectral profile of $10 \mathrm{~mm}$ long FBG in SMPOF

The fibre was exposed to the laser beam with the second lens in the system to expand the laser beam for a total of 15.5 minutes. The resulting fibre Bragg grating is shown in figure 6. The resulting grating had a length of $10 \mathrm{~mm}$, a returned signal to noise ratio of $8 \mathrm{~dB}$, a wavelength of $1579.5 \mathrm{~nm}$ and a full width half maximum (FWHM) value of $1.1 \mathrm{~nm}$.

\subsection{Microstructured POF}

Microstrcutured polymer optical fibre $\mathrm{mPOF}$ is constructed of a single material with the effective cladding arising due to the presence of a series of holes which run along the length of the fibre ${ }^{7,8}$. The endlessly single mode microstructured polymer optical fibre was constructed solely of PMMA, had a core size of $13 \mu \mathrm{m}$ with an outer fibre diameter of 150 $\mu \mathrm{m}$. The holey region consisted of 60 holes with diameters of 2.7 and separation of $8.8 \mu \mathrm{m}$ resulting in the ratio of hole diameter to spacing, $\mathrm{d} / \Lambda$, being 0.31 ; see figure 7 .

Polishing the ends of the mPOF pushes the residue from the process up into the holes. Since the holes are then filled with a material of a very similar refractive index to the polymer, the condition for light guiding is dramatically reduced and insufficient light can be transmitted through the fibre. A technique demonstrated by Law et al eliminates the need for polishing by heating the fibre and a razor blade to between $70-80{ }^{\circ} \mathrm{C}^{9}$. The end of the fibre is then cleaved using the razor blade. Cleaving at room temperature results in a rough end face leading to difficulties coupling light into the fibre. 


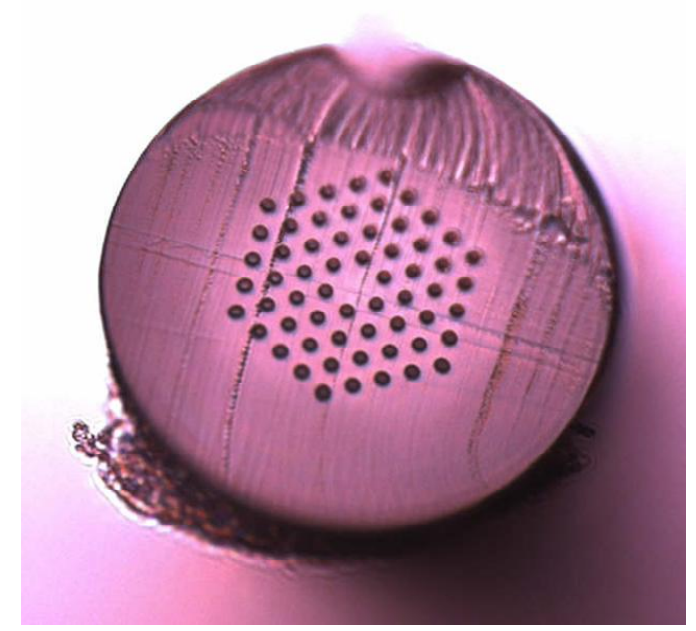

Figure 7: Microscope image of SMmPOF

The fabrication of fibre Bragg gratings in mPOF has recently been reported ${ }^{10}$. It was found that for successful grating inscription, the orientation of the photonic crystal with respect to the laser beam was important. Inspection of the back reflections of the $\mathrm{HeCd}$ laser beam from the fibre (on the screen in figure 5) revealed different diffraction patterns depending on the orientation of the fibre; one thin and bright and the other broad and dull. It was found that the pattern required for successful grating manufacture was the thin bright pattern.

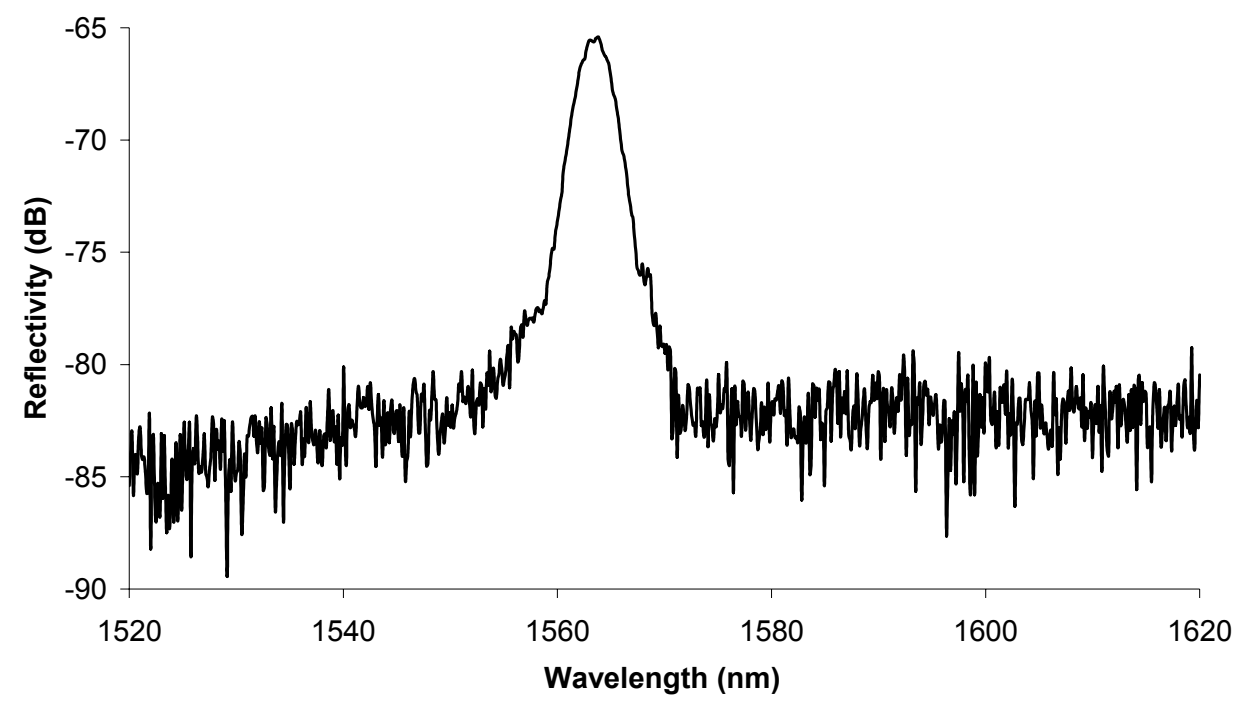

Figure 8: Spectral profile of $1 \mathrm{~mm}$ long FBG in SMmPOF

A fibre Bragg grating was fabricated in the mPOF without the additional lens in the system. The resulting spectral profile is shown in figure 8. Grating inscription required 18 minutes to reach saturation, the final Bragg wavelength was $1563.8 \mathrm{~nm}$, the FWHM $4 \mathrm{~nm}$ and the signal to noise ratio in reflection $17.1 \mathrm{~dB}$. 


\section{TEMPERATURE SENSITIVITY}

The temperature sensitivity of FBGS in POF has previously been studied by Lui et $a l^{11}$. They found the polymer fibre Bragg grating to have a negative temperature coefficient, corresponding to a blue wavelength shift occurring with increasing temperatures. However, the upper working limits of the gratings and the effects of temperature cycling on the room temperature spectral location were not studied. To investigate these effects, both gratings were interrogated using the arrangement shown in figure 9 .

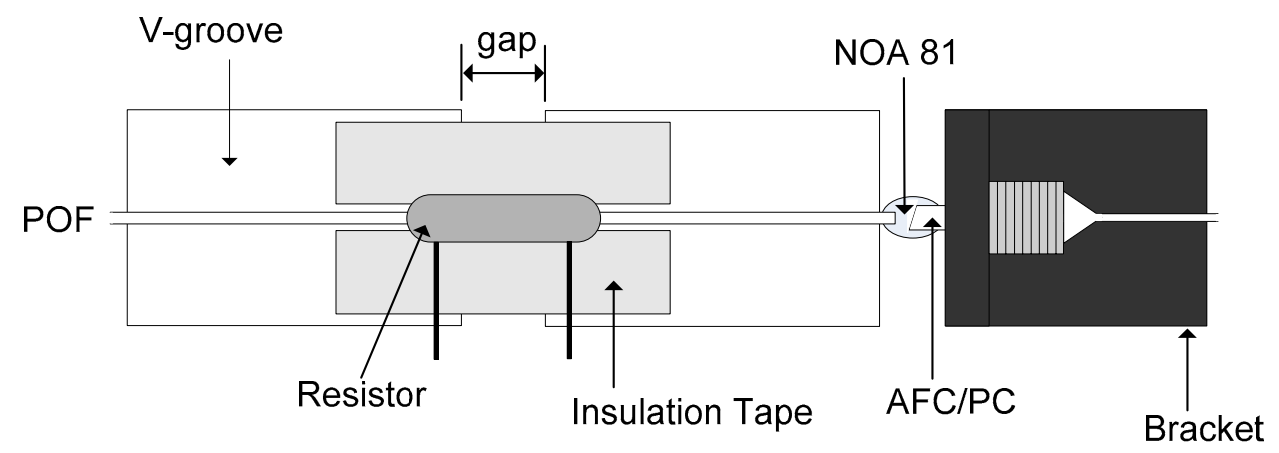

Figure 9: Arrangement of heating equipment for temperature characterisation of POF

The FBG was positioned so that it was located in the gap between two v-grooves, ensuring that there was no overlap of the grating on to the metal. To ensure the optical launch conditions remained constant during the investigations, the POF and ACF/PC connector were glued together using Norland Optical Adhesive (No. 81). A high power resistor was placed over the top of the FBG to achieve joule heating of the device. Finally, the area was enclosed by a polystyrene hood to help ensure a uniform equilibrium temperature could be reached. The temperature inside the hood was calibrated using a thermocouple for different values of current passing through the resistor.

\subsection{Step index POF}

In order to ensure thermal equilibrium, each temperature setting was held for 15 minutes and then the spectral shift recorded. Between each temperature setting the grating was returned to room temperature to ascertain if there was any change in the spectral location of the grating as a result of the temperature cycling. The temperature sensitivity of the FBG can be seen in figure 10 .

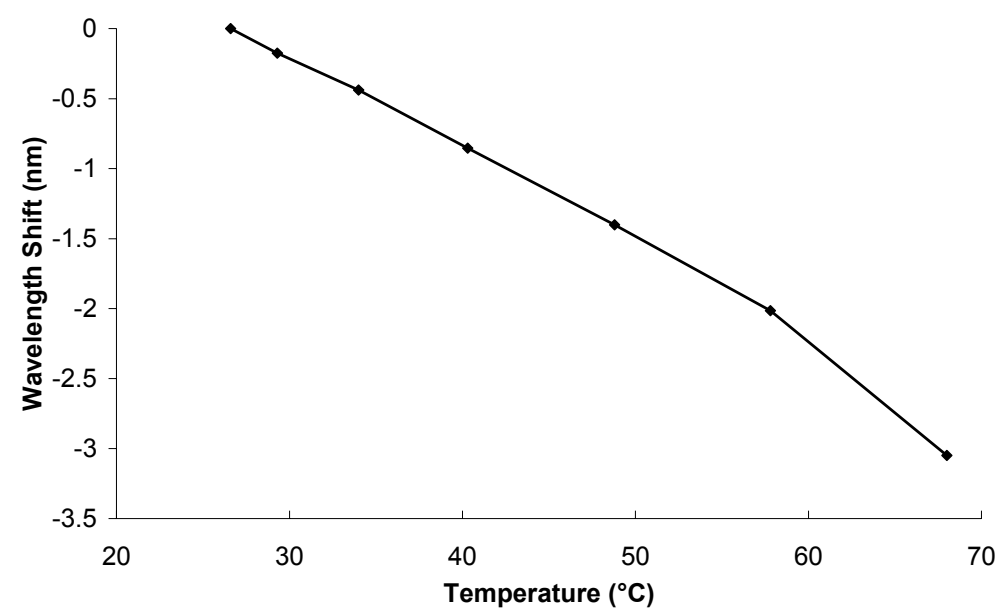

Figure 10: Temperature sensitivity of the FBG in SMPOF 
Figure 10 shows a total wavelength shift of $3 \mathrm{~nm}$ over the temperature range of 26.6 to $68{ }^{\circ} \mathrm{C}$. It also shows an approximately linear temperature response of $64.4 \mathrm{pm} /{ }^{\circ} \mathrm{C}$ between $26.6-57.8^{\circ} \mathrm{C}$ followed by an increasing sensitivity of $101 \mathrm{pm} /{ }^{\circ} \mathrm{C}$ between $57.8-68^{\circ} \mathrm{C}$. Both of these values compare favourably against the $\sim 10 \mathrm{pm} /{ }^{\circ} \mathrm{C}$ achieved by silica-based optical fibres. Increasing the temperature between $68-80.3^{\circ} \mathrm{C}$ resulted in the grating being permanently erased.

The hysteresis observed in the room temperature spectral location of the grating after each consecutive temperature setting is shown in figure 11. It can be seen from this figure that after heating to $57.8{ }^{\circ} \mathrm{C}$ the grating no longer returns to its original spectral location indicating a permanent change in the fibre. With increasing temperatures, this effect becomes more prominent with the spectral location shifting further away from its original position. A hystersis of 0.83 nm was observed before the grating was erased.

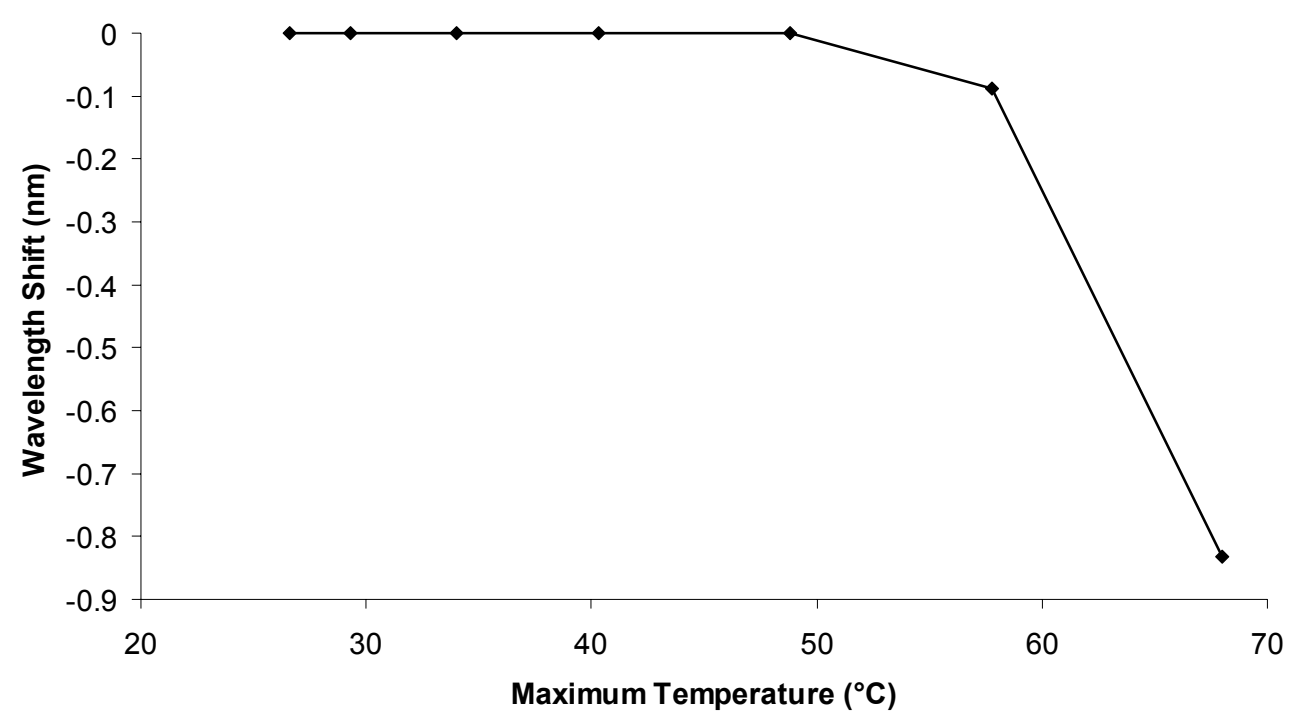

Figure 11: The shift in room temperature spectral location of the grating after each consecutive heating. The $\mathrm{x}$-axis depicts the temperature the grating was heated to before returning to room temperature.

\subsection{Microstructured POF}

The grating fabricated in the mPOF was investigated using the same technique as used for the step index fibre. An important difference between the two investigated fibres is that the grating in $\mathrm{mPOF}$ was able to survive temperatures of up to $106.1{ }^{\circ} \mathrm{C}$. This might be due to the lower glass transition temperatures of the ethyl-and benzyl-methacrylate used in the step index fibre core. The spectral profiles at room temperature and at $106.1^{\circ} \mathrm{C}$ of the mPOF grating are shown in figure 12 .

A total wavelength shift of about $21.5 \mathrm{~nm}$ was observed. After the initial results, the experiment was repeated to see if the same spectral shift could be attained. The temperature sensitivity of the initial and secondary heating of the grating can be seen in figure 13. Note that the graph shows the wavelength shift from room temperature and that the second heating cycle starts from a different wavelength as a result of hysteresis similar to that shown in figure 11 . The temperature sensitivity of the secondary temperature cycling was measured to be $-63.3 \mathrm{pm} /{ }^{\circ} \mathrm{C}$ which is comparable with the temperature sensitivity measured for the step index POF $\left(-64.4 \mathrm{pm} /{ }^{\circ} \mathrm{C}\right)$. 


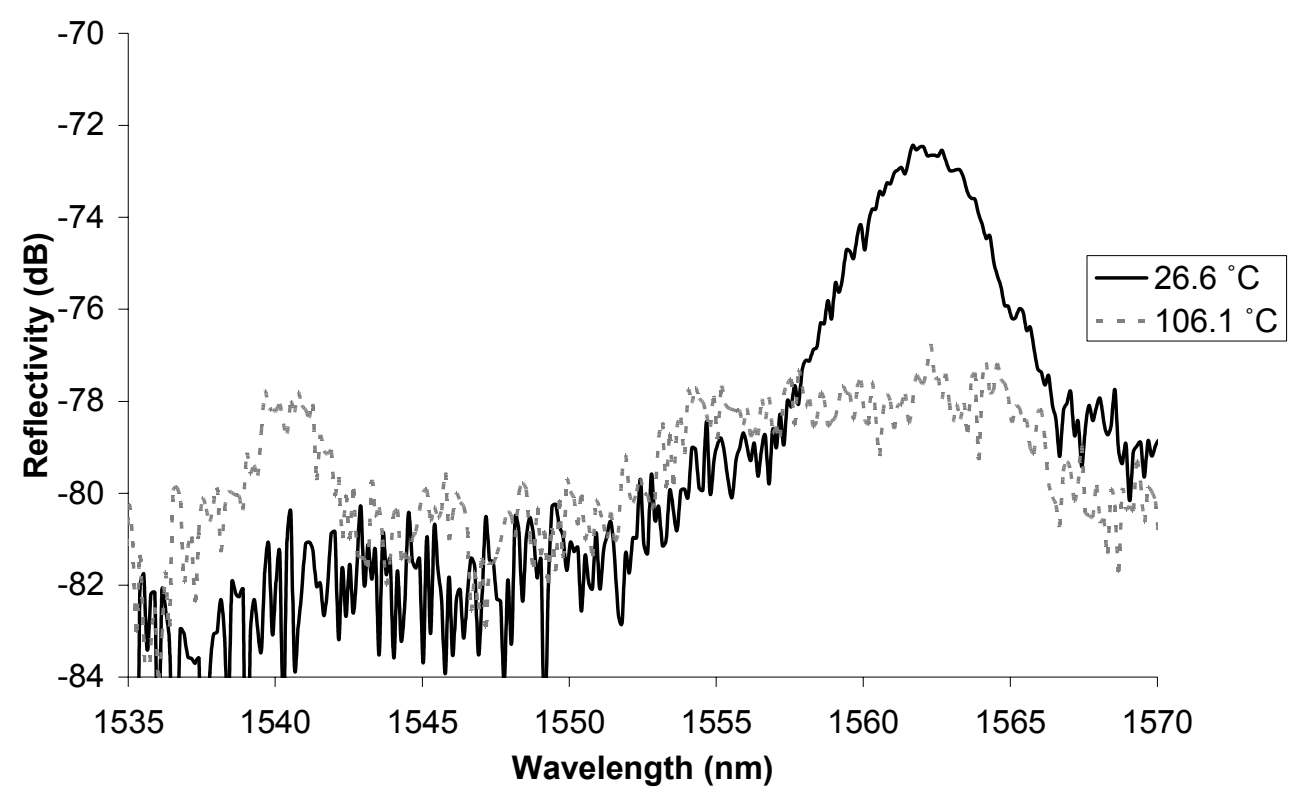

Figure 12: Graph showing the grating in $\mathrm{mPOF}$ at $26.6^{\circ} \mathrm{C}$ and at $106.1^{\circ} \mathrm{C}$

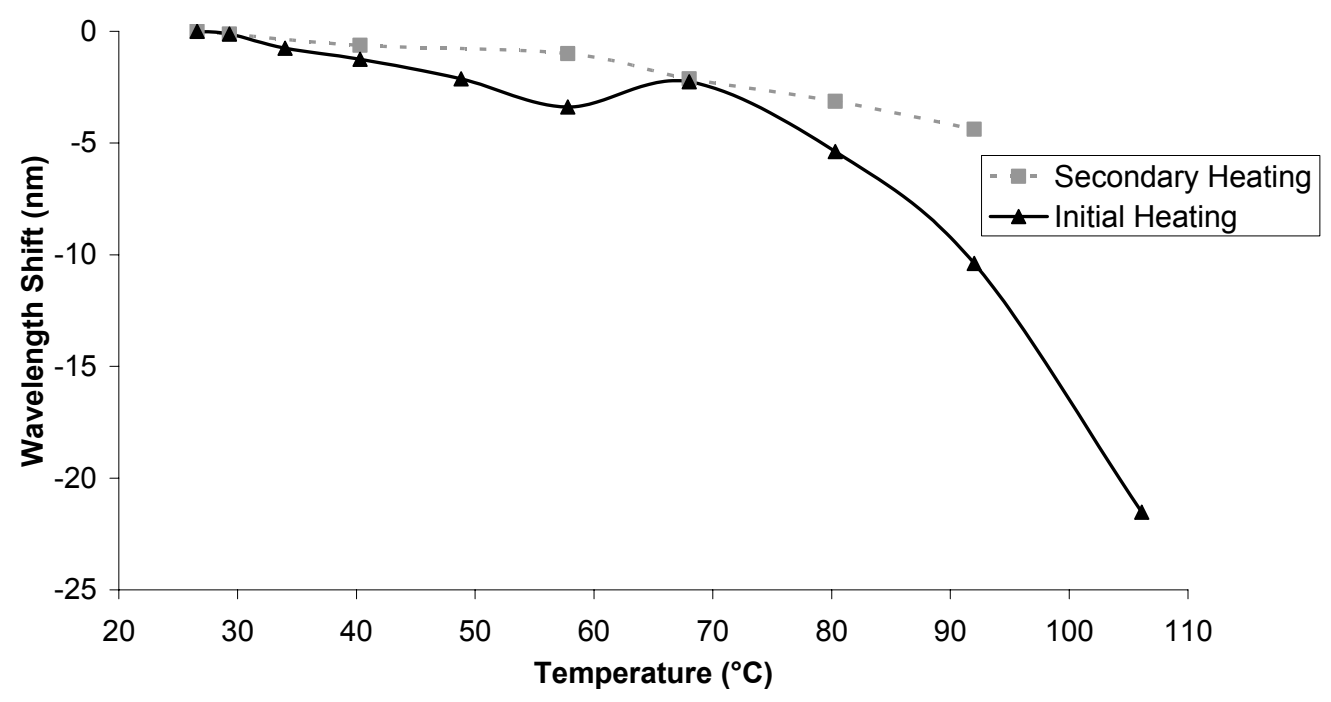

Figure 13: Temperature sensitivity of a FBG in mPOF.

The hysteresis of the spectral location of the grating at room temperature was again investigated after each temperature setting for both the initial and secondary heating. Large hysteresis was found for the grating on initial heating with the spectral location at room temperature shifting by $19 \mathrm{~nm}$; see figure 14 . However, no hysteresis was observed on the secondary temperature investigation, indicating a permanent change in the nature of the optical fibre. This observation provides hope that reliable and linear grating behaviour with temperature can be achieved using a suitable annealing schedule. 


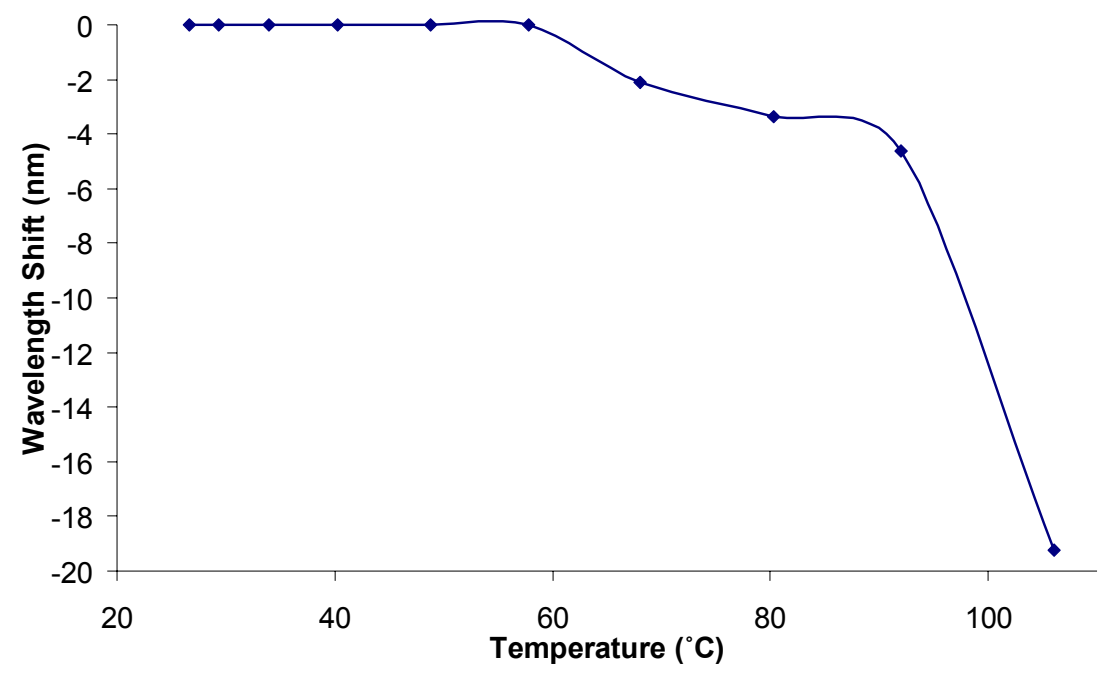

Figure 14: The shift in room temperature spectral location of the mPOF grating after each consecutive heating. The $\mathrm{x}$-axis depicts the temperature the grating was heated to before returning to room temperature.

There are two features apparent in figure 14. The most striking is the large shift in wavelength that occurs around 100 ${ }^{\circ} \mathrm{C}$, while the second is the smaller shift that begins around $60{ }^{\circ} \mathrm{C}$. The former is likely to be linked to the change in material properties that occur in the region of the glass transition temperature, which is around $105{ }^{\circ} \mathrm{C}$ for PMMA. The former may be related to the brittle to ductile transition that occurs around this temperature and which was invoked as a possible explanation for the change in cleaving behaviour with temperature reported by Law et $a l^{9}$. In fact both features are also present in the temperature dependence of the Young's modulus of PMMA ${ }^{12}$.

\section{CONCLUSIONS}

We have tried to highlight the differences between polymer fibre based FBGs and their silica counterparts from a reliability and repeatability perspective. In the case of the polymer devices, there are more factors that can influence the ultimate behaviour of the device and there is clearly a considerable amount of research to be done before all these factors are fully understood and reliable, well characterised devices are readily available. Nevertheless, we believe that the advantages that polymer fibre can bring for certain applications argue in favour of undertaking that research.

\section{ACKNOWLEDGEMENTS}

The authors would like to thank for support the UK Engineering and Physical Sciences Research Council and the EU Eureka project POLYFILTRO.

\section{REFERENCES}

${ }^{1}$ HY Liu, GD Peng and PL Chu, IEEE Photonics Technology Letters, 13, 824, (2001)

${ }^{2}$ Z. Xiong, G. D. Peng, B. Wu and P. L. Chu, "Highly tunable single-mode polymer optical fibre grating", IEEE Photonic Technology Letters, 11, 3, 352-354, 1999

${ }^{3}$ GD Peng, PL Chu, Z Xiong, TW Whitbread and RP Chaplin, "Dye-doped step-index polymer optical fiber for broadband optical amplification," Journal of Lightwave Technology, 14, 10, 99. 2215-2223, 1996

${ }^{4} \mathrm{http://www.amariplastics.com/} \mathrm{[accessed} 5^{\text {th }}$ March 2006]

5 http://www.rapra.net/ [accessed $5^{\text {th }}$ March 2006]

6 T Ishigure, M Hirai, M Sato and Y Koike, "Graded-index plastic optical fiber with high mechanical properties enabling easy network installations. I,” Journal of Applied Polymer Science, 91, pp. 404-409, 2004

${ }^{7}$ T.A. Birks, J.C.Knight and P.St.J. Russell. 'Endlessly single-mode photonic crystal fiber.' Optics Letters, 22 (13) (1997): 961-963 
${ }^{8}$ M.A. van Eijkelenborg, M.C.J. Large, A. Argyros, J. Zagari, S. Manos, N.A. Issa, I. Bassett, S. Fleming, R.C. Mcphedran, C. Martijn de Sterke and N.A.P. Nicorovici. 'Microstructured polymer optical fibre.' Optics Express, 9 (7) (2001): 319-327

${ }^{9}$ S.H. Law, J.D. Harvey, R.J. Kruhlak, M. Song, E. Wu, G.W. Barton, M.A. van Eijkelenborg, M.C.J. Large, "Cleaving of microstructured polymer optical fibres" Optics Communications, 258, 2, pp. 193-202, 2006

${ }^{10}$ H. Dobb, D.J. Webb, K. Kalli, A. Argyros, M.C.J. Large and M.A. van Eijkelenborg. 'CW UV light induced fibre Bragg gratings in few- and single-moded microstructured polymer optical fibre.' Optics Letters, 30 (24) (2005): 3296-3298

${ }^{11}$ H. Y. Liu, G. D. Peng and P. L. Chu, "Thermal tunability of polymer optical fibre Bragg gratings", IEEE Photonic Technology Letters, Vol.13, No.8, pp.824-826, August 2001

${ }^{12}$ Slide 7 in http://biomems.uta.edu/Research/Poster\%202-1 files/frame.htm [accessed 5th March 2006]. 